\title{
Tendon Injuries in the Hands in Rock Climbers: Epidemiology, Anatomy, Biomechanics and Treatment - An Update
}

\author{
V. Schöffl'1,2,3,4, I. Schöffl 4,5, L. Frank ${ }^{6}$, T. Küpper ${ }^{7}$, M. Simon ${ }^{1}$, C. Lutter ${ }^{8}$ \\ 1 Section Sportsorthopedics and Sportsmedicine, Department of Orthopedic and Trauma Surgery, Klinikum \\ Bamberg, Bamberg, FRG, Germany \\ 2 Department of Trauma Surgery, Friedrich Alexander University of Erlangen-Nuremberg, FRG, Germany \\ 3 Section of Wilderness Medicine, Department of Emergency Medicine, University of Colorado School of \\ Medicine, Denver, USA \\ ${ }^{4}$ School of Clinical and Applied Sciences, Leeds Becket University, Leeds, UK \\ ${ }^{5}$ Department of Pediatric Cardiology, Friedrich Alexander University Erlangen-Nuremberg, FRG, Germany \\ ${ }^{6}$ Medical School, Friedrich Alexander University Erlangen-Nuremberg, FRG, Germany \\ 7 Institute of Occupational \& Social Medicine, RWTH Aachen Technical University, FRG, Germany \\ 8 Department of Orthopedic and Trauma Surgery, Klinikum Bamberg, FRG, Germany \\ 9 Department of Orthopedics, Rostock University Medical Center, Rostock, FRG, Germany
}

\section{CORRESPONDING AUTHOR:}

\section{Volker Schöffl}

Section Sportsorthopedics and Sportsmedicine

Department of Orthopedic and

Trauma Surgery Klinikum Bamberg

FRG Bugerstraße 80, 96049

Bamberg, Germany

E-mail: volker.schoeffl@me.com

DOI:

10.32098/mltj.02.2020.08

LEVEL OF EVIDENCE: 2B

\begin{abstract}
SUMMARY
Background. Over the last decade, rock climbing has become an increasingly popular sport. With the latest inclusion into the Olympic program, this trend will continue upward. Lately, specific tendon injuries on the hand (e.g. lumbricalis tendon injuries or tenosynovitis) are reported to be on the rise within climbing patients.

Design. Clinical cohort study and comparison with literature data. Review of current therapeutic concepts.

Methods. Tendon injuries to the hands of rock climbers were identified from our climbers patient database over the years of 2017/18. These were compared to the numbers of 20092012 and 1998-2001. The injuries were analyzed, and the results were compared with the current literature.

Results. Within the ten most frequent injuries over the years 2017 and 2018, three were to the tendons and tendon sheath/pulleys. In a longitudinal comparison of patients in a climbing-specific sports medical clinic, the pulley injury is consistently the most frequent injury, followed by tenosynovitis and capsulitis of the finger joints.

Conclusions. In rock climbers, tendon injuries of the hand are frequent and many of these specific to the sport. Special knowledge about their pathology, diagnostics and treatment is necessary as some of these injuries rarely occur in non-climbing patients. With the further advent of climbing, an increase in injury incidence is to be expected.
\end{abstract}

\section{KEY WORDS}

Sport climbing; pulley injury; tenosynovitis; lumbrical tear; pulley tear; finger injury

\section{INTRODUCTION}

Over the last decade, indoor rock climbing has become an increasingly popular sport world-wide (1-3). With the latest inclusion in the Olympic program (Tokyo 2020), this trend will most likely continue (4). The outdoor rock climb- ing grades are also pushed even further and big rock faces such as "El Capitan" (Yosemite Valley, US) are even getting climbed free solo. With further increases in the popularity of competitive sport climbing, an increase in injury rate and severity may be expected $(2,5)$. While the most frequent 
acute injuries in rock climbing (especially bouldering) are ankle strains and fractures $(1-3,6,7)$, most chronic injuries affect the upper extremity- predominantly the hand (3, 7-11). These injuries require specific attention as they are unique to this group of athletes (12). Lately, specific tendon injuries (e.g. lumbricalis tendon injuries (13) or tenosynovitis $(4,14,15))$ are reported to be on the rise while other injuries to the tendons of the hand, pulley and tendon sheath, such as pulley ruptures or tenosynovitis are constantly the most frequent chronic injuries in rock climbing athletes (3, $6,8,15-17)$. Secondary injuries also occur in the hand, such as fractures of the hamate hook, based on the high forces applied to the finger flexor tendons (18). The following article focuses on the epidemiology as well as the differential diagnosis and treatment of tendon injuries of the hand in rock climbers. While for the epidemiology our climbing specific database was used as the primary source, the diagnostic and treatment criteria will be described as a review of the current literature.

\section{METHODS}

Based on our continuously ongoing database of rock climbing injuries seen and treated in our sports medical clinic, we identified climbers with hand tendon injuries during 2017-2018. These were to be compared to the numbers of 2009-2012 (19) and 1998-2001 (12). After identifying these patients, our treatment files of the injuries were analyzed, and the results of our findings were to be compared with the current literature. Therefore, a comprehensive search of the literature was conducted using the MEDLINE/PubMed and Cochrane databases. The search was performed in March 2019 without date limits to identify studies that reported on specific injuries to the tendons in the hand in rock climbers. Different combinations of the terms, finger injuries, climbing injuries, tendon injuries, rock climbing, sport climbing, hand injuries and bouldering were used. We included experimental and original papers, systematic and non-systematic reviews, case-reports, and book chapters, independent of their level of evidence. Reference lists from the included articles were also reviewed by hand. The identified papers were first screened and then analyzed for which ones focused specifically on hand tendon injuries in rock climbers.

\section{RESULTS}

The current literature presents only two sets of analyses of similar patient groups. Nelson et al. (1) analysed climbing injuries treated in American hospitals or emergency rooms from 1990 to 2007 using the NEISS database. They report- ed that the majority of acute injuries were to the lower extremity, primarily the ankles. Meanwhile, overexertion injuries were more likely to occur to the upper extremities. In a recent analysis, based on the same NEISS database approach, Buzzacott et al. (2) looked into the consecutive years of 2008 to 2016. They also reported that the most frequently injured body parts were the lower extremities $(47 \%)$, followed by upper extremities $(25 \%)$. Unfortunately, finger and hand injuries were not further evaluated in these studies. Thus, these analyses of 25 years of climbing injuries fail to show trends in hand injuries. The other series of comparable published climbing patient cohorts are our analyses of climbing patients, seen in our sports medicine clinic.

From 1998 to 2001, we evaluated 604 climbing injuries (20) and from 2009 to 2012, 911 climbing injuries (15). For the actual evaluation, we analyzed the data of 2017 - 2018, to evaluate possible new trends after climbing's inclusion into the Olympics. This longitudinal comparison of patients in a climbing specific Sports Medical clinic consistently shows the pulley injury as the most frequent injury, followed by tenosynovitis and capsulitis of the finger joints (table I). Shoulder and knee injuries are on the rise, while epicondylitis is declining. Also, lumbrical muscle injuries are among the 10 most common diagnoses of climbing patients. It needs to be stated that these three analyses do have a selection bias, as they do not represent a cross-section of all climbing injuries, but a cross-section of climbing-specific injuries which are treated by a specialized center (15). While traumatic injuries (e.g. an ankle fracture) are likely treated by the closest trauma center available, patients with pulley ruptures or other finger injuries are more likely to seek a second opinion in our clinic (15). Within the finger injuries (table II), epiphyseal injuries are also on the rise. Injuries to the flexor tendons and their pulley / tendon sheath (pulley injuries, tenosynovitis) make the 2 most frequent finger injuries.

\section{DISCUSSION}

\section{Anatomy and Biomechanics}

The flexor- and extensor tendons must be looked at separately in anatomical regards, even though the tendons of e.g., the lumbricalis muscles take an exceptional position (8).

\section{The extensor tendons}

The long fingers have four common extensor tendons as well as two tendons which are dedicated to a single finger - extensor indices for the 2nd digit and extensor digiti minimi for the 5 th digit. The tendon of the extensor digiti minimi runs through the 5 th tendon compartment, while 
Table I. The 10 most frequent climbing injuries - epidemiological development over 20 years $(15,20)$.

\begin{tabular}{|c|c|c|c|c|c|c|c|c|}
\hline Injuries 2017-2018 $(\mathrm{n}=582)$ & $\mathrm{n}$ & 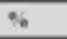 & Injuries $2009-2012(\mathrm{n}=911) \mathrm{n}$ & $\mathrm{u}$ & 5 & Injuries 1998-2001 $(\mathrm{n}=604) \mathrm{t}$ & n & $\%$ \\
\hline Pulley injury & 72 & 12,4 & Pulley ingury & 140 & 15.4 & Palley injuxy & 122 & 20.2 \\
\hline Teaosynowitis & 68 & 11.7 & Capsulitis & 87 & 9.5 & Epicondylitis & 51 & 8,4 \\
\hline Knee igjury & 42 & 7.2 & SLAP tear & 51 & 5.6 & Strain finger joist capsule & 37 & 6,1 \\
\hline SL_AP tear & 37 & 6.4 & Epicondylitis & so & 5.5 & Skin abrasions & 34 & 5.6 \\
\hline Impingement (shoulder) & 34 & 5,8 & Inpingement (shoulder) & 40 & 4,4 & Back problems & 24 & 4,0 \\
\hline Spinal injuries & 18 & 3.1 & Strain finger joint capsiale & 25 & 2,7 & Capselitis. & 13 & 2,2 \\
\hline Lumbrical tmsscle tear & 12 & 2.1 & Ganglion finger flexot teadou 1 & & 2,1 & Ganglica finger flexor tendos 1 & 11 & 1,8 \\
\hline
\end{tabular}

Table II. The 10 most frequent finger injuries 2017-2018 $(n=251), 2009-2012(n=474)$ and 1998-2001 $(247)(15,20)$.

\begin{tabular}{|c|c|c|c|c|c|c|c|c|}
\hline & $\begin{array}{l}2017- \\
2018\end{array}$ & & & $\begin{array}{l}2009- \\
2012\end{array}$ & & & $\begin{array}{l}1998- \\
2001\end{array}$ & \\
\hline $\begin{array}{l}\text { Finger injuries } \\
(n=251)\end{array}$ & & & $\begin{array}{l}\text { Finger injuries } \\
(n=474)\end{array}$ & $\mathrm{n}$ & $\%^{*}$ & $\begin{array}{l}\text { Finger injuries } \\
(n=247)\end{array}$ & $n$ & $\%^{*}$ \\
\hline Pulley injury & 78 & 31.1 & Pulley injury & 140 & 29.5 & Pulley injury & 122 & 49.4 \\
\hline $\begin{array}{l}\text { Tenosynovitis flexor } \\
\text { tendon }\end{array}$ & 69 & 27.5 & Capsulitis & 87 & 18.4 & Tenosynovitis & 42 & 17.0 \\
\hline Capsulitis & 49 & 19.5 & $\begin{array}{l}\text { Tenosynovitis flexor } \\
\text { tendon }\end{array}$ & 80 & 16.9 & $\begin{array}{l}\text { Strain finger joint } \\
\text { capsule }\end{array}$ & 37 & 15.0 \\
\hline Epiphyseal fracture & 19 & 7.6 & Strain flexor tendon & 36 & 7.6 & Capsulitis & 13 & 5.3 \\
\hline $\begin{array}{l}\text { Lumbrical tear / } \\
\text { strain }\end{array}$ & 12 & 4.8 & $\begin{array}{l}\text { Strain finger joint } \\
\text { capsule }\end{array}$ & 25 & 5.3 & Ganglion & 11 & 4.5 \\
\hline $\begin{array}{l}\text { Strain finger joint } \\
\text { capsule }\end{array}$ & 10 & 4.0 & $\begin{array}{l}\text { Ganglion finger flexor } \\
\text { tendon }\end{array}$ & 19 & 4.0 & Strain flexor tendon & 7 & 2.8 \\
\hline Osteoarthritis & 4 & 1.6 & Lumbrical tear / strain & 19 & 4.0 & Fracture & 7 & 2.8 \\
\hline $\begin{array}{l}\text { Strain finger joint } \\
\text { capsule }\end{array}$ & 4 & 1.6 & $\begin{array}{l}\text { Collateral ligament } \\
\text { injury }\end{array}$ & 17 & 3.6 & Osteoarthritis & 7 & 2.8 \\
\hline Ganglion & 3 & 1.2 & Epiphyseal fracture & 16 & 3.4 & Soft tissue injury & 5 & 2.0 \\
\hline Contusion & 3 & 1.2 & Osteoarthritis & 14 & 3.0 & Tendon rupture & 4 & 1.6 \\
\hline
\end{tabular}

all other tendons run through the 4 th compartment (8). On the level of the dorsum of the hand and the metacarpophalangeal joints, there are many cross-connections known as the connexi intertendinei. At the proximal interphalangeal joint (PIP) the extensor tendons separate into two lateral reins and one central rein (tractus intermedius). Together, these tendons form the so-called extrinsic system- tendons of muscles which originate proximal of the hand itself (8). The extrinsic system is supported by the intrinsic system, muscles originated within in the hand, the $\mathrm{mm}$. lumbricales, the $\mathrm{mm}$. interossei and the thenar and hypothenar muscles (8). 


\section{The flexor tendons and their functional system with the pulley and tendon sheath}

Both flexor tendons of the long fingers, the flexor digitorum profundus (FDP) and flexor digitorum superficialis (FDS), run through the carpal tunnel and pulleys and intersect at the chiasm (8). The thumb flexor tendon (flexor pollicis longus) runs through the carpal tunnel on the radial aspect of the forearm and is strengthened by two pulleys. The muscle passes through an osteofibrous channel to the base of the distal phalanx (8).

The annular ligaments and the cruciate ligaments are seen as a reinforcement system of the flexor tendons along the osteofibrous channels of the fingers and are fixed to the phalanges (21). Five annular (A1-A5) and 3 weaker cruciate ligaments (C1-C3) are to be distinguished $(21,22)$ (figure 1). Pattern and arrangement of these ligaments vary $(22,23)$. All pulleys have different functions in stabilizing the flexor tendons at the palmar sides of the phalanges $(22,24-26)$. The main function of the flexor tendon pulley system is to hold the flexor tendons close to the bone, thus converting linear force into torque resulting in rotation at the interphalangeal (IP) and metacarpophalangaeal (MCP) joints (27). The A2 annular ligament plays the most important role in guidance of the flexor tendons, (28-31). A minor role in force transmission and tendon deflection is performed by the A1 and A5 pulleys (27). The pulley system suppresses the tendon excursion, and the force of the flexor tendons is transferred efficiently in flexion and hyperextension to reach the full range of motion (27). The lumbricalis and interossei are exceptions, as they originate from the flexor tendons themselves and end in the tendinous hood of the extensor tendons (13). Their function is flexion in the MCP and extension in the proximal (PIP) and distal interphalangeal joint (DIP) $(8,13,32)$.

Blood supply of the flexor tendons is guaranteed through the "vinculae tendinae" in the region of the osseous insertion of the tendon as well as in the osteofibrous channel (8, $13,32)$. Venous drainage is performed through the same system (8). Verdan (33) subsequently divided the flexor and extensor tendons into different regions of interest regarding injuries, prognosis and nutrition (34).

A differentiation between the thumb and the index finger is also necessary. The flexor tendon of the thumb (flexor pollicis longus) runs through the carpal tunnel on the radial side of the forearm, and strengthened by 2 pulleys, the muscle passes through an osteofibrous channel to the basis of the distal phalanx (8).

\section{Injury patterns}

Injury patterns are differentiated into open or closed, sharp or blunt, traumatic or degenerative lesions, as well as injury to the dorsal or palmar surface (8). Open injuries to the tendons in rock climbing are rare $(8,12,15)$ and only happen due to a direct trauma to the skin and underlying tendons. These may result in ruptured tendons or more seriously in finger avulsion amputations, due to the rope performing a loop and the respective finger getting caught within it while the rope tensions in a fall $(12,35,36)$. Another possible injury mechanism is a finger getting stuck in a finger pocket and excessively bending, leading to an open injury or a blunt tendon disruption (37). Closed injuries are more frequent in climbers and most often occur acutely to the finger flexor tendon pulleys or as a chronic injury to the

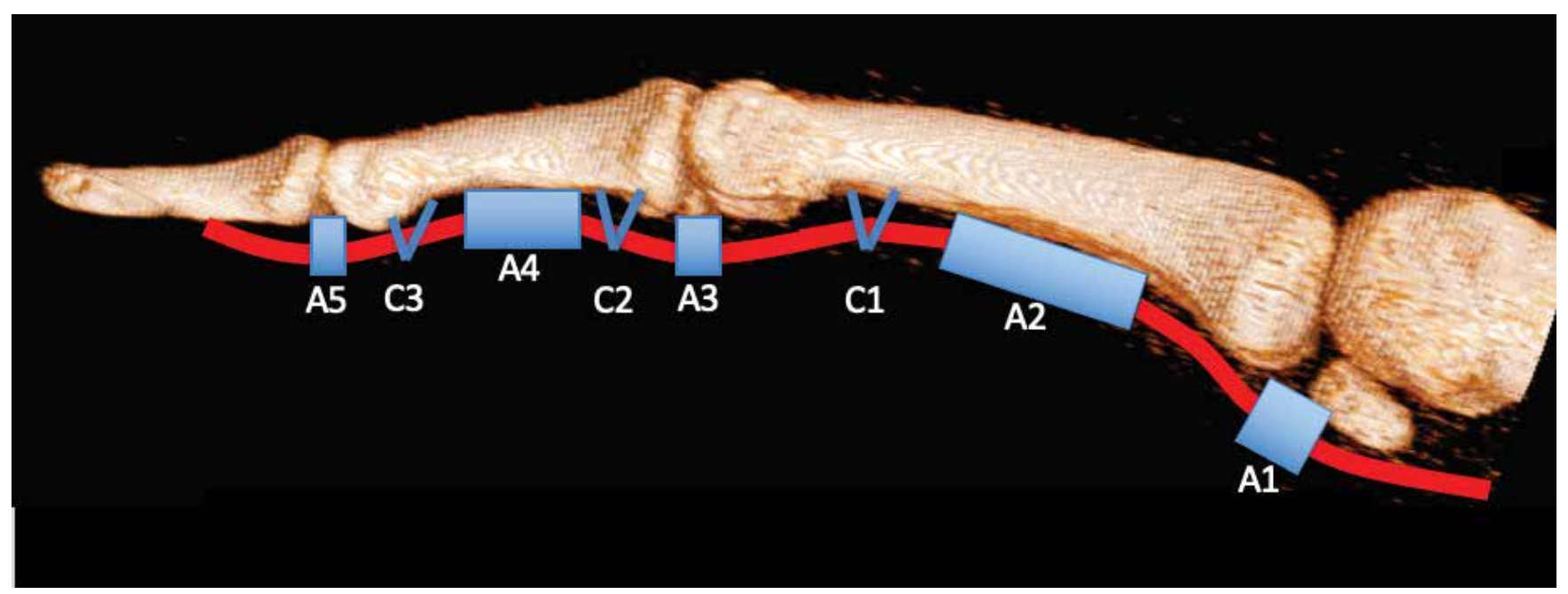

Figure 1. The pulley system of the finger flexor tendons. 


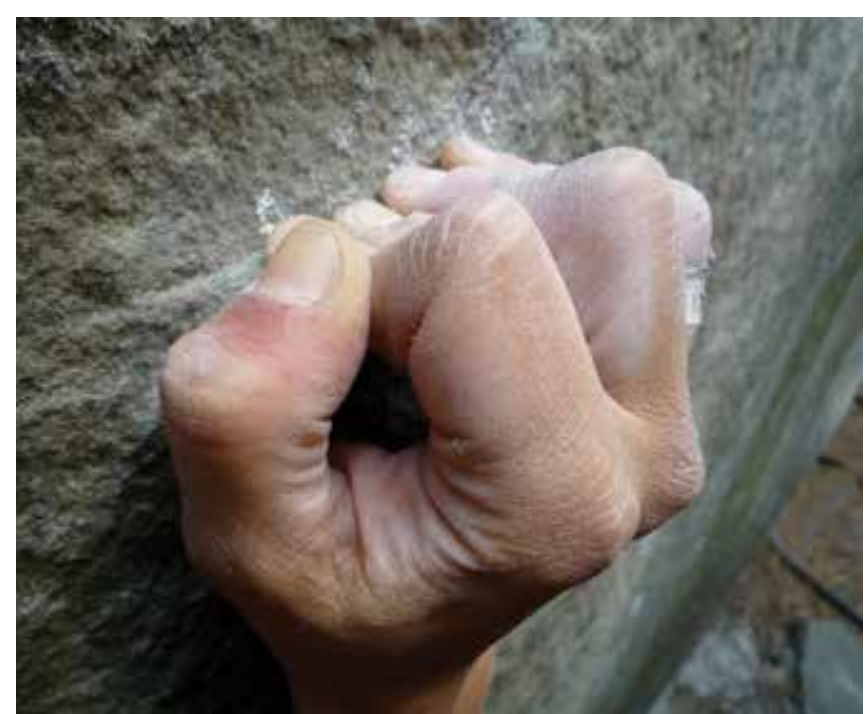

Figure 2. The crimp grip position.

tendon sheath (12). Various climbing holds can lead to various corresponding injuries $(21,24,25,27)$. The crimp grip position (figure 2) is well known to place high forces on the flexor tendon pulleys $(21,24,25,27)$. In addition, the eccentric movement of the fingers while climbing along with the and the friction beneath the pulleys, play a major role (24, 28,38 ). The hanging (sloper) finger position (figure 3 ) is more likely to cause flexor tendon strains and tears (12).

Tendon avulsions, first mentioned by von Zander (39) in 1989, mostly affect the insertion of the FDP-tendon at the distal phalanx (8). Usually, this injury is seen on the 4th finger, as the FDP-tendon is embedded inbetween the double-sided lumbrical tendons, as shown by Manske and Lesker (40) in cadaver dissection (8). We were able to verify this injury, especially in rock climbers, based on chronic degenerative damages to the tendon $(13,32)$.

\section{Diagnosis}

In clinical examinations of lacerations, one has to remember that even small cuts can cause severe damage underneath the surface. For example, a partial rupture of $90 \%$ of the tendon can seem to be functionally intact yet can then rupture secondarily after considerably minor stress $(8,41)$. The function of the FDS and FDP tendons needs to be examined separately. A pulley lesion may become apparent with a bowstring-phenomenon (42). In addition to the clinical examination, ultrasound and MRI are well-established tools to detect closed tendon injuries, as well as to assess injuries to the pulleys and tendon sheaths (12, 21, 43-49). Ultrasound is performed in a supine position with longi-

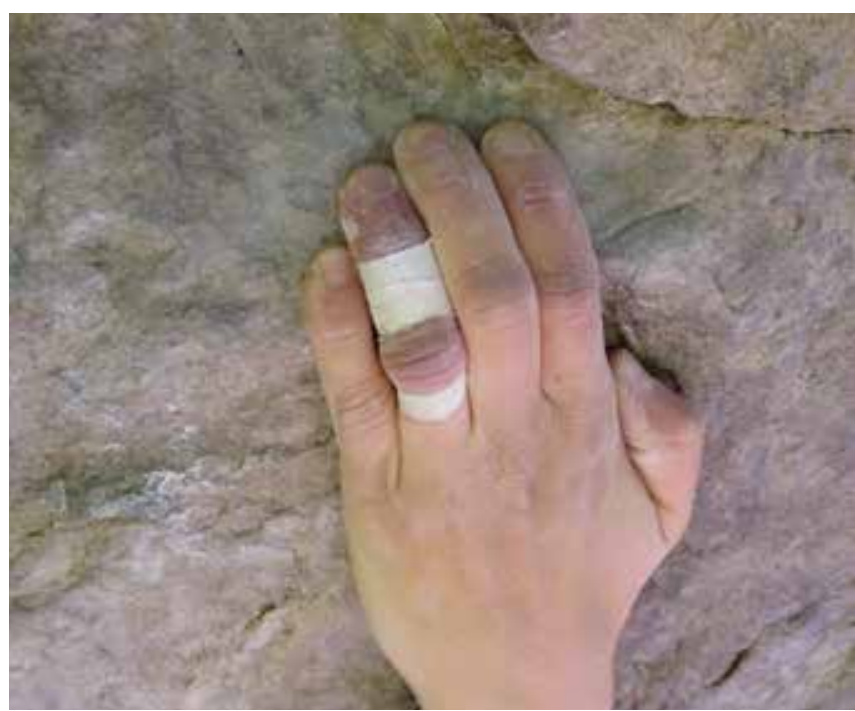

Figure 3. The hanging (sloper) finger position.

tudinal and transversal planes, using a linear transducer (13-18 MHz). For signal enhancement, a gel standoff pad is used or the examination is done in a warm water basin. Only in rare cases will an additional MRI (or CT) need to be performed $(21,42,47)$. A considerable advantage of the ultrasound is the possibility of dynamic examination, which can demonstrate tendon excursions through "forced flexion" better than a static method $(48,50,51)$. Additionally, inflammatory processes can easily be demonstrated (effusion, increased blood flow) and cellulitis, ganglion cysts, bone marrow edema and phlegmonia can be better visualized and detected $(46,49,52)$. Diagnosis of a pulley lesion is performed in forced flexion of the finger, meaning active pressure of the finger towards the transducer $(21,53)$. Thereby, quantifications of the enhanced distance between bone and flexor tendon, as seen in pulley ruptures, can be made $(21,53)$. A recent cadaver study showed that injuries to the A2 and A4 pulleys could be diagnosed via ultrasound with sensitivities of $90 \%$ and $94 \%$, and specificities of $100 \%$ and $97 \%$, respectively (45). An increased tendonbone distance of more than $2 \mathrm{~mm}$ in forced flexion is the general diagnostic criteria for a rupture (45). This cadaver study also proved the technique's capability in the diagnosis of A3 pulley injuries, using an increased distance of more than $0.09 \mathrm{~mm}$ between the flexor tendons and the volar plate (45). If the ultrasound fails to lead to a conclusion, an additional MRI should be performed. Using the MRI, a more specific differentiation of inflammatory processes or posttraumatic osseous edema can be made $(48,52)$. More recently, dynamic MRI techniques are becoming available $(43,44,54)$. 


\section{Differential diagnosis and treatment}

In the following section, the respective injuries and their essential therapeutic approach are presented. Nevertheless, focus is kept on the most frequent and climbing specific injuries.

\section{Pulley injuries}

As already stated, injuries to the finger flexor pulley system are the most common finger injury in rock climbers (15). Caused mainly through the crimping position (figure 2 ) the $\mathrm{A} 2$, A3 or A4 pulleys, which are considered the most important ones for this type of activity and prone to the highest stress level, can either be strained or ruptured (21). Usually only one of the finger flexor tendon pulleys disrupts-the A2 or the A4 pulley (37). Singular c-pulley ruptures rarely happen (55). A pulley injury in rock climbers was first described by Bollen and Tropet in $1990(56,57)$. Nowadays, closed pulley injuries are also reported in non-climbing patients (58).

The diagnosis of a pulley disruption is based on the history (pop or snapping sound) and the clinical examination, where a painful flexor tendon bowstringing can be palpated during resisted finger-flexion. The lift-off or bowstringing of the tendon is visualized by ultrasonography (50) or magnetic resonance imaging $(48,59)$. Single pulley-disruption are treated conservatively since Schöffl et al. (60) showed that also with non-operative management, no objective or subjective functional loss occurred $(3,21,37)$. The healing-time of the pulley is between 2 and 3 months and

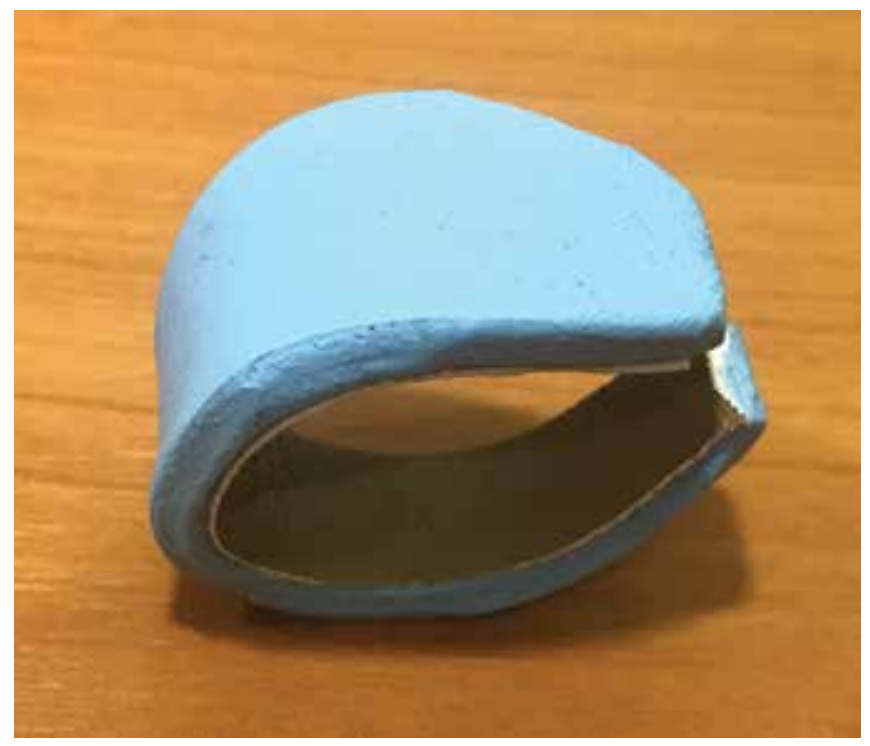

Figure 4. Pulley protection ring. full load-bearing can be expected after 4-6 months $(21,37$, 61). An injury involving multiple pulleys should receive a surgical repair as they otherwise lead to flexion contracture $(21,62,63)$.

For the conservative therapy, the use of a special pulley protection ring, which is formed in a way that the neuro-vascular bundles of the finger are out of compression, allowing an adequate reposition of the tendon without compromising circulation within the finger, is implemented for two months, followed by a pulley protection tape $(37,61)$ (figure 4). With this treatment regimen, Schneeberger and Schweizer (61) were able to reduce the initial bowstringing at the A2-pulley by $50 \%$ and at the A4-pulley by $40 \%$. If, however, two or more pulleys are disrupted, the amount of bowstringing increases substantially, leading to a loss of active flexion range of motion of the finger and a surgical pulley reconstruction has to be considered $(37,60)$. The results of such interventions are generally good and do not differ considerably between different surgical techniques $(64,65)$. Recently, the encircling techniques as an alternative approach showed the disadvantage of occasional bone loss $(66,67)$ and a transosseous modification was presented (62). . However, whether all these patients need a reconstruction at all is still being debated (37). We have seen a series of patients with multiple pulley ruptures who returned to their previous climbing level without restriction except for a small loss of flexion range of motion (37). This concept only works if there is no clinical bowstringing or early onset of contracture. The pulley support ring therapy must be started within a few days after the trauma and be performed strictly for 6 to 8 weeks. Overall, the general approach in multiple pulley injuries is still surgical. It also needs to be considered that pulley reconstruction leads to a rehabilitation time of several months.

Some concepts for prevention of pulley injuries exist. A general protective pulley-tape around an intact pulley is very unlikely to be effective in healthy fingers $(68,69)$ and showed evidence of even increasing injury risk (70). The main positive effect is that the PIP joint is not flexed more than $80-90^{\circ}$ if the tape is applied close or even over the PIP joint itself (37). More important is the correct warming-up procedure and the avoidance of a pronounced crimp grip position. It has been shown that over the first 120 climbing moves, the amount of physiological bowstringing of the flexor tendons shows an increase of up to $30 \%$ (37). Therefore, climbing about 3-4 routes with 40 moves or 8-12 boulder-problems with increasing intensity is recommended as a warm up (71). After a pulley injury, tape should be applied at either the distal end of the respective injured pulley (71) or as an H-tape at the level of the PIP joint (72). In some cases, the leftover trunk of the ruptured pulley can cause complications, leading to a tenosynovitis (Flap irritation 
phenomenon) (73). Figure 5 gives an overview of the therapeutic concept (42).

\section{Tenosynovitis}

Tenosynovitis (tendonitis, tendovaginitis) is the most important differential diagnosis to the pulley injury and the most frequent overuse syndrome in climbers fingers (20). It is commonly referred to as tendonitis by laypersons and climbers, but is in fact an inflammation of the tendon sheath $(12,74)$. An inflammatory response occurs after repetitive stress and its onset can either be both acute or chronic. The climber suffers from pain, occasionally accompanied by a minor swelling along the palmar surface of the digit, around the same area as a pulley injury. The pain can extend into the palm or the forearm. Diagnosis can be made through ultrasound which detects a "halo" phenomenon around the tendon $(12,50)(74)$ (figure 6). Increased accumulation of liquid around the tendon is most clearly visible in a transversal plane (53). As climbers tend to have more liquid in their flexor tendon sheets after high stress on various ranges, no clear information can be given about the normal range (12). It is best to compare the ultrasound finding of the injured finger to the same finger on the contra-lateral side (12). The therapy consists of anti-inflammatory medication, resting

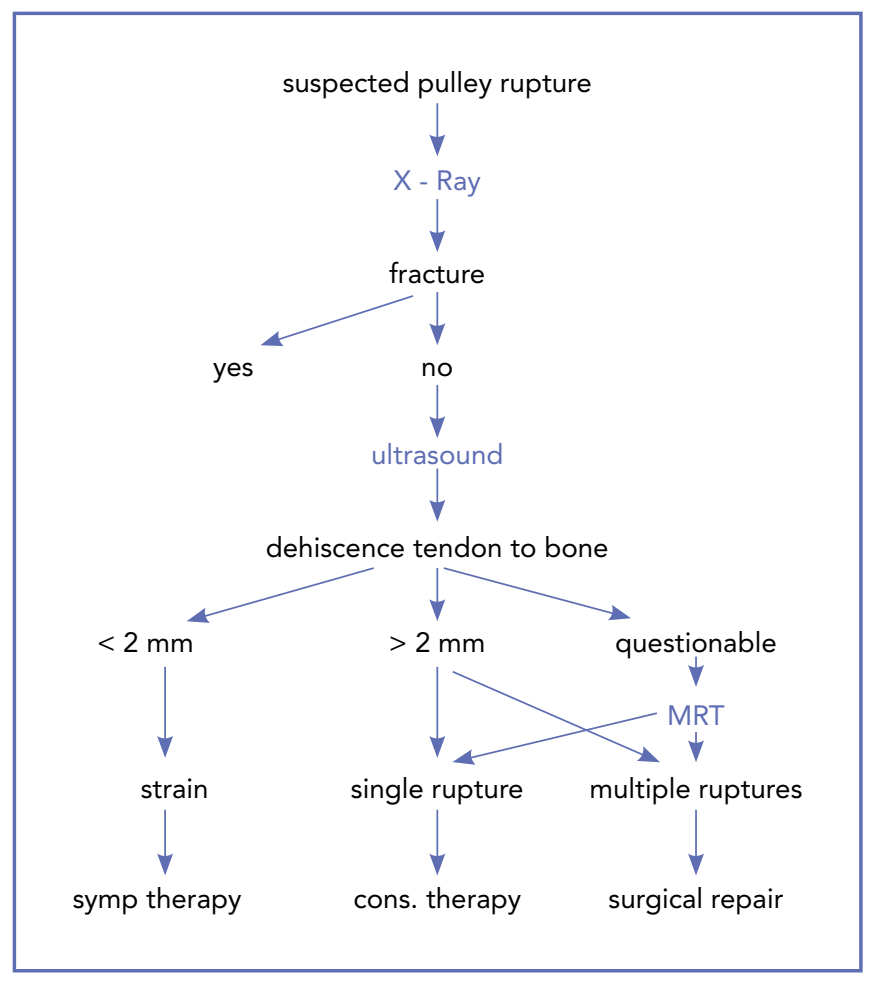

Figure 5. Therapeutic algorithm of pulley ruptures (42). on a splint for several days, external ointment applications, brush massages (with a toothbrush), ice therapy and, in a persisting condition, local cortisone injections $(9,12)$. These injections are not always avoidable, as the chronic tenosynovitis can be stubborn (12).

\section{Tendon strains and ruptures}

Directly injured tendons were observed in a few cases, most often caused by a sudden stress on a hand or finger in a hanging position (e.g. the foot slipping off a foothold) (12). Patients present with pain running along the course of the flexor tendon (35). This pain increases in the hanging position, while sometimes it can be totally gone in a crimp position. Diagnosis can be rather difficult, in which case ultrasound and MRI can be used. In flexor tendon strains, the recovery can be prolonged and the recurrence rate is high. Therapy is conservative combined with therapeutic ultrasound. In rare cases, a partial tear of the tendon occurs which can lead to tendon nodules and triggering $(75,76)$. Complete tendon tears are rare and require a surgical revision (figure 7). As they are mostly based on a degeneration of the tendon, a primary fusion may be advisable if the tear is at the level of the distal interphalangeal joint $(12,32,35)$.

\section{Lumbrical Shift Syndrome}

Lumbrical shift syndrome is a rather seldom, but very climbing-specific pathology which was first described by Schweizer (77). The incidence of a lumbrical muscle tear is increasing due to the popularity of climbing (13). It is caused by a so-called "quadriga effect", which describes a shear inju-

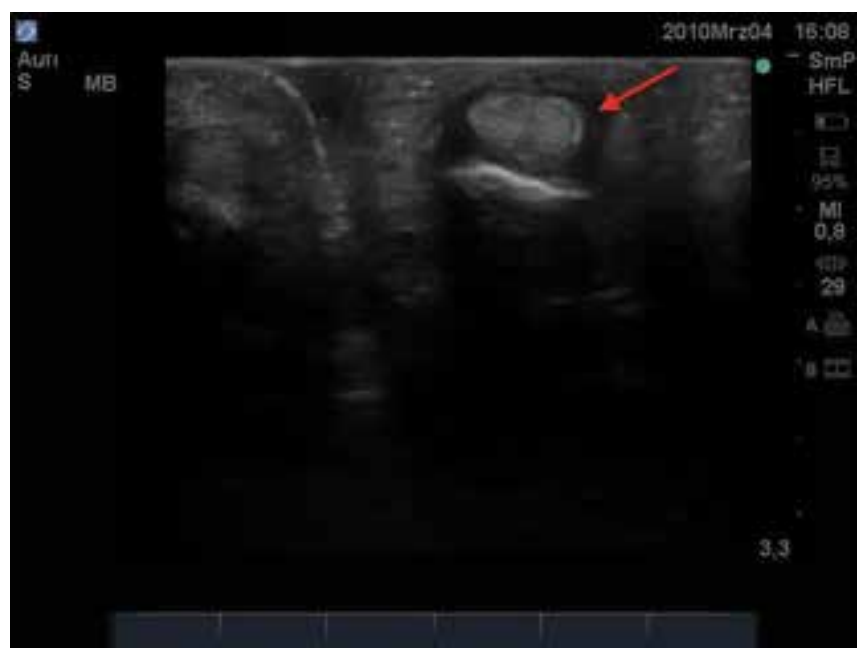

Figure 6. Halo-phenomen around the flexor tendon in ultrasound of tenosynovitis. 


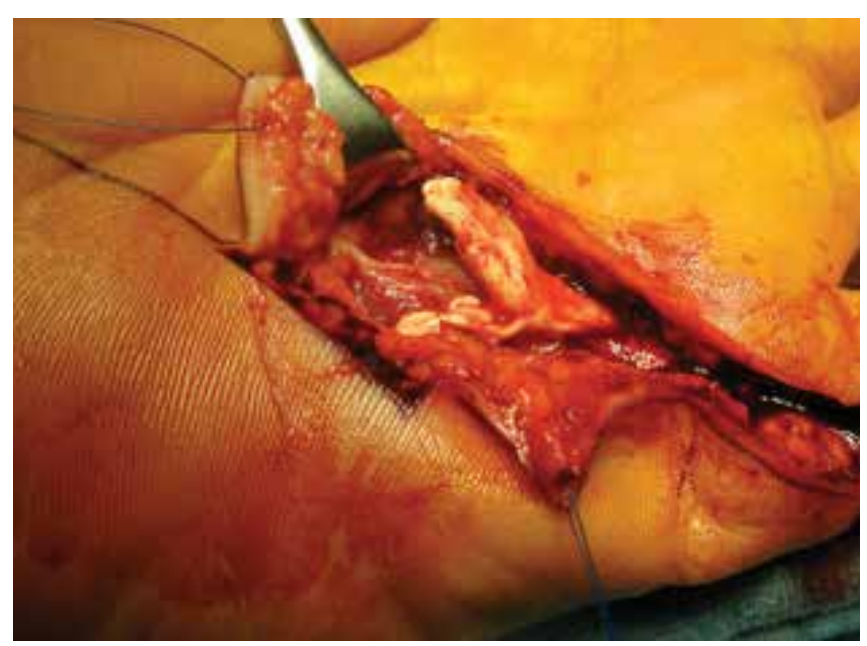

Figure 7. Complete tear of the profundus and superficial flexor tendons of the 5 th finger in a climber.

ry resulting from pathologic stress to the two origins of the bipennate lumbrical muscle $(13,78,79)$ (figure 8). This pathomechanism results from gripping positions of the hand in which one or two fingers are extended, while the neighbouring fingers are actively flexed $(78,79)$. This increases the maximum strength by up to $50 \%$ and causes a shift of the FDP tendons and its common muscle body of the various fingers against each other leading, to muscle strains or partial tears $(13,77)$. In the clinical examination, pain only becomes obvious if one finger is extended while the others are flexed. If the climber pulls with all fingers in extension, the pain is gone. Therapy consists of symptomatic treatment, taping and carefully stretching of the muscle (38). It is very important to start with stretching exercises immediately, which is done in the same way that the injury was provoked, but with much less load (37). Lutter et al. (13) reviewed data from 60 consecutive patients with a positive lumbrical stress tests which included clinical examination $(n=60 / 60)$, ultrasound ( $n=60 / 60)$, magnetic resonance imaging $(n=12 / 60)$ and outcome $(n=60 / 60)$. Lumbrical muscle tears were graded according to the severity of clinical and imaging findings as grade I-III injuries (13). The therapy consisted of adapted functional therapy (13). $30 \%$ of patients had grade I injuries (microtrauma), $53 \%$ had grade II injuries (muscle fibre disruption) and $16 \%$ had grade III injuries (musculotendinous disruption) (13). All patients had an uncomplicated outcome with complete recovery and unaffected return to climbing (13). The healing period in Grade III injuries was significantly longer than in the two other groups $(\mathrm{p}<0,001)$ (13). Based on their study Lutter et al. (13), a diagnostic and therapeutic algorithm is presented in figure 9.

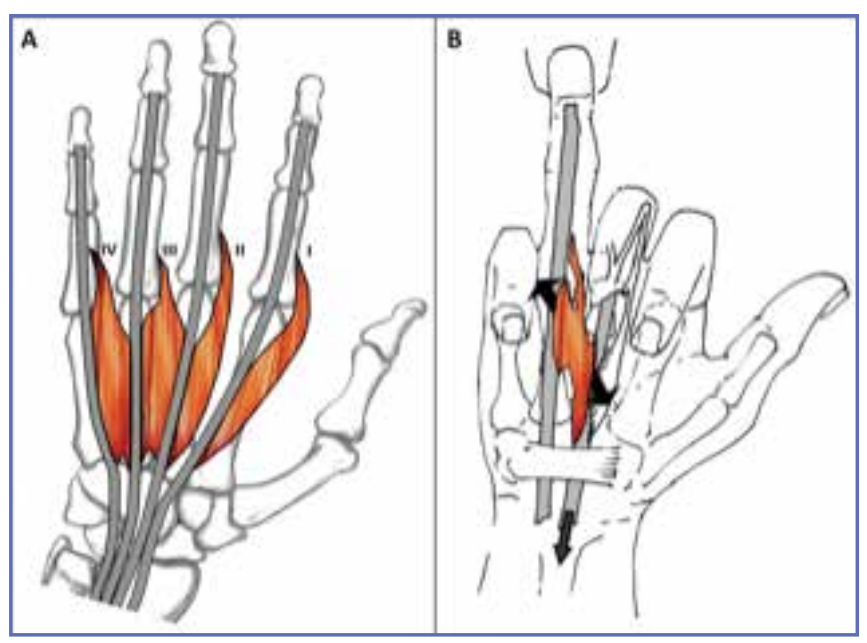

Figure 8. The "quadriga effect" in lumbrical muscle injury (13).

\section{Extensor hood syndrome}

In athletes with a long history of climbing activity, progressive osteoarthritic changes of the small finger joints have been observed (80-83). These changes can present as large bone spurs on both the flexor and extensor sides of the digits $(8,84)$. With intensive use of the crimp grip position during climbing, these bone spurs can produce irritation to the extensor tendons (84). Schöffl et al. (84) reported about 13 rock climbers in a 3 -year period complaining of dorsal-sided pain of the proximal and/or distal interphalangeal (PIP/DIP) joints. Plain radiographs revealed dorsal bone spurs (osteophytes) on the PIP joint in all climbers and on the DIP joint in three climbers (84). According to the Kellgren-Lawrence scale (85) the radiographs (in 7 cases bilateral) revealed 5 grade 2, 12 grade 3 and 3 grade 4 osteoarthritis. Each of these dorsal bone spurs were causing irritation to the extensor hood, resulting in fluid accumulation and tenosynovitis-like conditions even if the extensor tendons do not have true tendon sheaths, compared to the flexor tendons at the level of the DIP and PIP joints. In two cases, the dorsal osteophyte had already broken off (84). The therapy is primarily conservative with anti-inflammatory ointment dressings or local steroid injections; in rare cases, however, an operative excision of the dorsal sided bone spurs is necessary to release the stress from the extensor tendons (84).

\section{CONCLUSIONS}

Tendon injuries of the hand are frequent and sport-specific injuries in rock climbers. Specific knowledge about their 


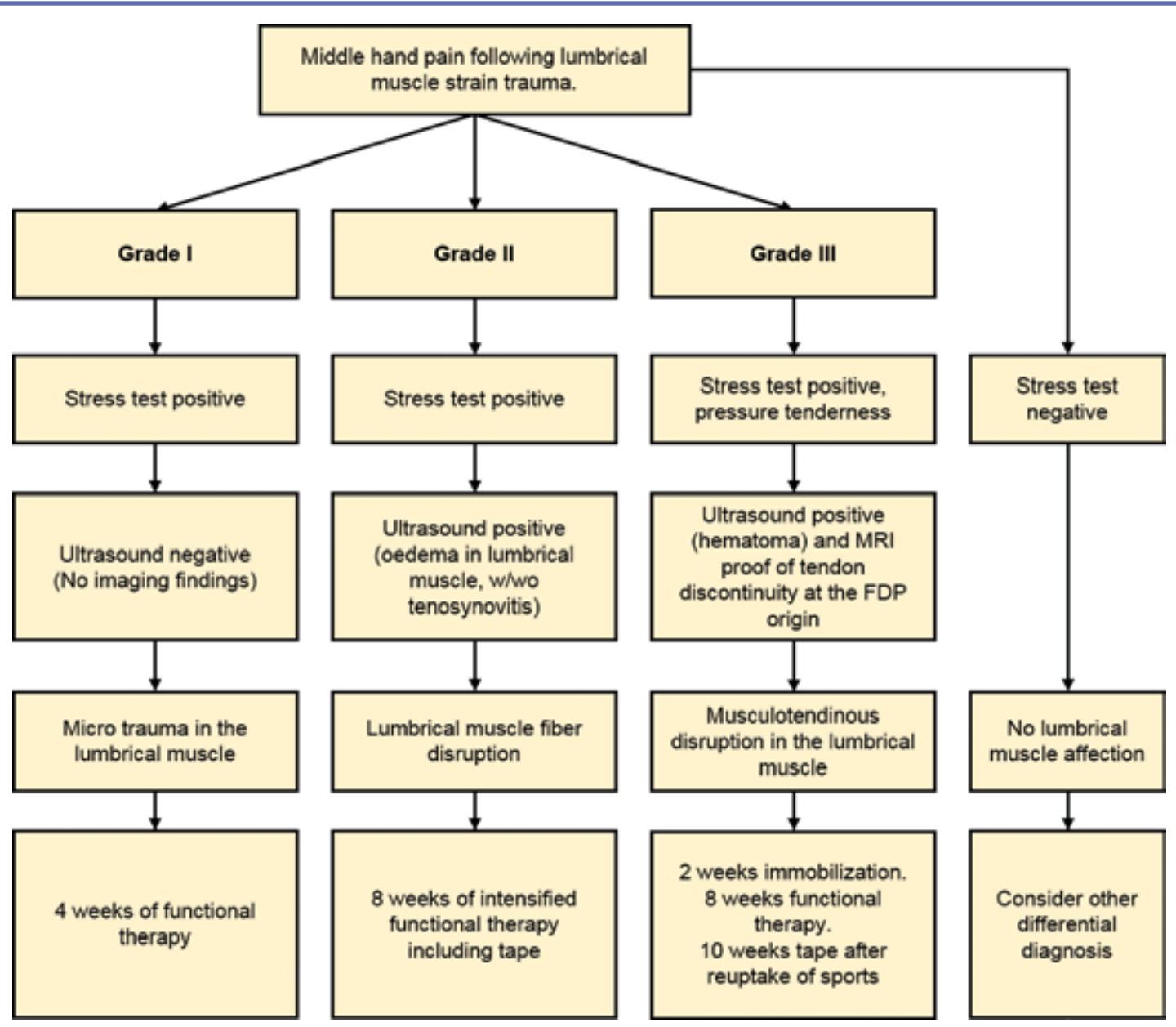

Figure 9. Diagnostic and therapeutic algorithm for lumbrical muscle injuries (13).

pathology as well as diagnostics and treatment is necessary, as some of these injuries only rarely occur in non-climbing patients. With the further advent of climbing, and with the expected further increase in overall training load due to the sports inclusion in the Olympic program, a further increase in injury incidence is expected. Thus further work regard- ing tendon injury prevention and the possible effects of compensatory training is necessary (70).

\section{CONFLICT OF INTERESTS}

The authors declare that they have no conflict of interests.

\section{REFERENCES}

1. Nelson NG, McKenzie LB. Rock climbing injuries treated in emergency departments in the U.S., 1990-2007. American journal of preventive medicine. 2009;37(3):195-200.

2. Buzzacott P, Schöffl I, Chimiak J, Schöffl V. Rock climbing injuries treated in US emergency departments, 2008-2016. Wilderness Environ Med. 2019.

3. Jones G, Schöffl V, Johnson MI. Incidence, Diagnosis, and Management of Injury in Sport Climbing and Bouldering: A Critical Review. Curr Sports Med Rep. 2018;17(11):396-401.
4. Lutter C, El-Sheikh Y, Schöffl I, Schoffl V. Sport climbing: medical considerations for this new Olympic discipline. Br J Sports Med. 2017;51(1):2-3.

5. Schöffl V, Lutter C. The "Newbie" Syndrome. Wilderness Environ Med. 2017;28(4):377-80.

6. McDonald JW, Henrie AM, Teramoto M, Medina E, Willick SE. Descriptive Epidemiology, Medical Evaluation, and Outcomes of Rock Climbing Injuries. Wilderness Environ Med. 2017;28(3):185-96. 
7. Schöffl V, Morrison AB, Schwarz U, Schöffl I, Küpper T. Evaluation of injury and fatality risk in rock and ice climbing. Sport Med. 2010;40(8):657-79.

8. Schöffl V, Heid A, Kupper T. Tendon injuries of the hand. World journal of orthopedics. 2012;3(6):62-9.

9. Jones G, Johnson M. A critical review of the incidence and risk factors for finger injuries in rock climbing. Curr Sports Med Rep. 2016;15(6):400-9.

10. Gronhaug G, Norberg M. First overview on chronic injuries in sport climbing: proposal for a change in reporting of injuries in climbing. BMJ Open Sport Exerc Med. 2016;2(1):e000083.

11. Pozzi A, Pivato G, Pegoli L. Hand Injury in Rock Climbing: Literature Review. J Hand Surg Asian Pac Vol. 2016;21(1):13-7.

12. Schöffl VR, Schöffl I. Finger pain in rock climbers: reaching the right differential diagnosis and therapy. J Sports Med Phys Fitness. 2007;47(1):70-8.

13. Lutter C, Schweizer A, Schöffl V, Römer F, Bayer T. Lumbrical muscle tear: clinical presentation, imaging findings and outcome. J Hand Surg (Eu). 2018.

14. Schöffl V. Rock and Ice-Climbing Medicine. In: Feletti F, editor. Extreme Sports Medicine. 1. Switzerland: Springer International Publishing; 2017. p. 109-21.

15. Schöffl V, Popp D, Küpper T, Schöffl I. Injury distribution in rock climbers - A prospective evaluation of 911 injuries between 2009-2012. Wilderness Environ Med. 2015;26(1):62-7.

16. Schöffl V, Morrison A, Schöffl I, Küpper T. Epidemiology of injury in mountainering, rock and iceclimbing. In: Caine D, Heggie T, editors. Medicine and Sport Science - Epidemiology of Injury in Adventure and Extreme Sports. 58: Karger; 2012. p. 17-43.

17. Grønhaug G. Self-reported chronic injuries in climbing: who gets injured when? BMJ Open Sport Exerc Med. 2018;4(1):e000406. doi: 10.1136/bmjsem-2018-. eCollection 2018.

18. Lutter C, Schweizer A, Hochholzer T, Bayer T, Schoffl V. Pulling Harder than the Hamate Tolerates: Evaluation of Hamate Injuries in Rock Climbing and Bouldering. Wilderness Environ Med. 2016;27(4):492-9.

19. Schöffl VR, Hoffmann G, Kupper T. Acute injury risk and severity in indoor climbing-a prospective analysis of 515,337 indoor climbing wall visits in 5 years. Wilderness Environ Med. 2013;24(3):187-94.

20. Schöffl V, Hochholzer T, Winkelmann HP, Strecker W. [Differential diagnosis of finger pain in sport climbers] Differentialdiagnose von Fingerschmerzen bei Sportkletterern. D Z Sportmed. 2003;54:38-43.

21. Schöffl V, Schöffl I. Injuries to the Finger Flexor Pulley System in Rock Climbers - Current Concepts. J Hand Surg [Am]. 2006;31(4):647-54.

22. Doyle JR. Anatomy of the finger flexor tendon sheath and pulley system. J Hand Surg [Am]. 1988;13(4):473-84.

23. Hahn P, Lanz U. [Flexor pulleys of the fingers. Anatomy, biomechanics, reconstruction] Die Ringbänder der Fingerbeugesehnen. Anatmoie, Biomechanik, Wiederherstellung. Handchir Mikrochir Plast Chir. 1996;28(5):265-70.

24. Schöffl I, Oppelt K, Jungert J, Schweizer A, Bayer T, Neuhuber W, et al. The influence of concentric and eccentric loading on the finger pulley system. J Biomech. 2009.

25. Schöffl I, Oppelt K, Jungert J, Schweizer A, Neuhuber W, Schöffl V. The influence of the crimp and slope grip position on the finger pulley system. J Biomech. 2009.
26. Manske PR, Lesker PA. Strength of human pulleys. Hand. 1977;9(2):147-52.

27. Roloff I, Schöffl VR, Vigouroux L, Quaine F. Biomechanical Model for the determination of the forces acting on the finger pulley system. J Biomech. 2006;39(5):915-23.

28. An KN, Berglund L, Uchiyama S, Coert JH. Measurement of friction between pulley and flexor tendon. Biomed Sci Instrum. 1993;29:1-7.

29. Lin GT, Cooney WP, Amadio PC, An KN. Mechanical properties of human pulleys. J Hand Surg [Br]. 1990;15(4):429-34.

30. Lin GT, Amadio PC, An KN, Cooney WP. Functional anatomy of the human digital flexor pulley system. J Hand Surg [Am]. 1989;14(6):949-56.

31. Doyle JR. Anatomy of the flexor tendon sheath and pulley system: a current review. J Hand Surg [Am]. 1989;14(2 Pt 2):349-51.

32. Schöffl V, Winkelmann HP. [Traumatic and degenerative tendon lesions of the hand]. Der Orthopade. 2010;39(12):1108 16.

33. Verdan CE. Primary and secondary repair of flexor and extensor tendon injuries. In: Flynn JE, editor. Hand Surgery. Baltimore: Williams \& Willkins; 1966. p. 220-42.

34. Voigt C. Sehnenverletzungen an der Hand. Chirurg. 2002;73:744-67.

35. Schöffl V, Hochholzer T, Lightner S. One move too many. Boulder CO, USA: Sharp End Publishing; 2016.

36. Vandeputte G, Dubert T. Closed traumatic rupture of the flexor pulleys of a long finger associated with avulsion of the flexor digitorum superficialis. J Hand Surg [Br]. 2001;26(3):266-8.

37. Schöffl V, Schweizer A. Sportclimbing related injuries and overuse syndromes. In: Seifert L, Wolf P, Schweizer A, editors. IRCRA Handbook of climbing \& mountaineering from science to performance. Research in sport and exercise science. London, New York: Routledge; 2016. p. 59-75.

38. Schweizer A, Frank O, Ochsner PE, Jacob HA. Friction between human finger flexor tendons and pulleys at high loads. J Biomech. 2003;36(1):63-71.

39. VonZander. Trommlerlähmung. Berlin1891.

40. Manske PR, Lesker PA. Avulsion of the ring finger flexor digitorum profundus tendon: an experimental study. Hand. 1978;10(1):52-5.

41. Boyer MI, Strickland JW, Engles D, Sachar K, Leversedge FJ. Flexor tendon repair and rehabilitation: state of the art in 2002. Instructional course lectures. 2003;52:137-61.

42. Schöffl V, Hochholzer T, Winkelmann HP, Strecker W. Pulley injuries in rock climbers. Wilderness Environ Med. 2003;14(2):94-100.

43. Bayer T, Fries S, Schweizer A, Schoffl I, Janka R, Bongartz G. Stress examination of flexor tendon pulley rupture in the crimp grip position: a 1.5-Tesla MRI cadaver study. Skeletal Radiol.44(1):77-84

44. Bayer T, Adler W, Schweizer A, Schoffl I, Uder M, Janka R. Evaluation of finger A3 pulley rupture in the crimp grip position-a magnetic resonance imaging cadaver study. Skeletal Radiol.44(9):1279-85.

45. Schöffl I, Deeg J, Lutter C, Bayer T, Schöffl V. Diagnosis of A3 Pulley Injuries Using Ultrasound. Sportverletz Sportschaden. 2018;32(4):251-9.

46. Garcia K, Jaramillo D, Rubesova E. Ultrasound evaluation of stress injuries and physiological adaptations in the fingers 
of adolescent competitive rock climbers. Pediatr Radiol. 2017;48(3):366-73.

47. Martinoli C, Bianchi S, Cotten A. Imaging of rock climbing injuries. Semin Musculoskelet Radiol. 2005;9(4):334-45.

48. Bodner G, Rudisch A, Gabl M, Judmaier W, Springer P, Klauser A. Diagnosis of digital flexor tendon annular pulley disruption: comparison of high frequency ultrasound and MRI. Ultraschall Med. 1999;20(4):131-6.

49. McGeorge DD, McGeorge S. Diagnostic medical ultrasound in the management of hand injuries. J Hand Surg [Br]. 1990;15:256-61.

50. Klauser A, Frauscher F, Bodner G, Halpern EJ, Schocke MF, Springer P, et al. Finger pulley injuries in extreme rock climbers: depiction with dynamic US. Radiology. 2002;222(3):755-61.

51. Klauser A, Frauscher F, Bodner G, Cihak C, Gabl M, Schocke $\mathrm{M}$, et al. [Value of high-resolution ultrasound in the evaluation of finger injuries in extreme sport climbers]. Ultraschall Med. 2000;21(2):73-8.

52. Lutter C, Hochholzer T, Bayer T, Schoffl V. Rock Climbing-Related Bone Marrow Edema of the Hand: A Follow-up Study. Clin J Sport Med. 2018;28(4):382-8.

53. Klauser A, Stadlbauer KH, Frauscher F, Herold M, Klima $G$, Schirmer $M$, et al. Value of transducer positions in the measurement of finger flexor tendon thickness by sonography. J Ultrasound Med. 2004;23(3):331-7.

54. Bayer T, Schweizer A, Muller-Gerbl M, Bongartz G. Proximal interphalangeal joint volar plate configuration in the crimp grip position. The Journal of hand surgery. 2012;37(5):899-905.

55. Schöffl V, Schöffl I. Isolated cruciate pulley ruptures in rock climbers. J Hand Surgery (European). 2010;35:245-6.

56. Bollen SR. Injury to the A2 pulley in rock climbers. J Hand Surg [Br]. 1990;15(2):268-70.

57. Tropet Y, Menez D, Balmat P, Pem R, Vichard P. Closed traumatic rupture of the ring finger flexor tendon pulley. J Hand Surg [Am]. 1990;15(5):745-7.

58. Schöffl V, Jüngert J. Closed Flexor Pulley Injuries in Non-Climbing Activities. J Hand Surg [Am]. 2006;31(5):806-10.

59. Lutter C, Hochholzer T, Bayer T, Schoffl V. Rock Climbing-Related Bone Marrow Edema of the Hand: A Follow-up Study. Clin J Sport Med. 2017.

60. Schoffl VR, Schoffl I. Injuries to the finger flexor pulley system in rock climbers: current concepts. J Hand Surg [Am]. 2006;31(4):647-54.

61. Schneeberger M, Schweizer A. Pulley Ruptures in Rock Climbers: Outcome of Conservative Treatment With the Pulley-Protection Splint; A Series of 47 Cases. Wilderness Environ Med. 2016;27(2):211-8.

62. Schöffl I, Meisel J, Lutter C, Schöffl V. Feasibility of a New Pulley Repair: A Cadaver Study. Journal of Hand Surgery. 2018;43(4):380.e1 - .e7.

63. Schöffl V, Küpper T, Hartmann J, Schöffl I. Surgical repair of multiple pulley injuries - evaluation of a new combined pulley repair. J Hand Surg [Am]. 2012;37(2):224-30.

64. Arora R, Fritz D, Zimmermann R, Lutz M, Kamelger F, Klauser AS, et al. Reconstruction of the digital flexor pulley system: a retrospective comparison of two methods of treatment. J Hand Surg [Br]. 2007;32(1):60-6.

65. Schöffl V, Küpper T, Hartmann J, Schöffl I. Surgical repair of multiple pulley injuries - evaluation of a new combined pulley repair (in press). J Hand Surg [Am]. 2012.
66. Lutter C, Schoeffl V. Intermittent unspecific osteitis and cortex atrophy of the proximal phalanx after surgical pulley repair. BMJ case reports. 2015;2015.

67. Lin GT. Bone resorption of the proximal phalanx after tendon pulley reconstruction. J Hand Surg [Am]. 1999;24(6):1323-6.

68. Schweizer A. Biomechanical effectiveness of taping the A2 pulley in rock climbers. J Hand Surg [Br]. 2000;25(1):102-7.

69. Warme WJ, Brooks D. The effect of circumferential taping on flexor tendon pulley failure in rock climbers. Am J Sports Med. 2000;28(5):674-8.

70. Schöffl V, Lutter C, Wollings K, Schöffl I. Pediatric and adolescent injury in rock climbing. Res Sports Med. 2018;26(sup1):91-113.

71. Schweizer A. Biomechanical properties of the crimp grip position in rock climbers. J Biomech. 2001;34(2):217-23.

72. Schöffl I, Einwag F, Strecker W, Hennig F, Schöffl V. Impact of Taping after Finger Flexor Tendon Pulley Ruptures in Rock Climbers. J Apl Biomech. 2007;23:52-62.

73. Schöffl I, Baier T, Schöffl V. Flap irritation phenomenon (FLIP): etiology of chronic tenosynovitis after finger pulley rupture. Journal of applied biomechanics. 2011;27(4):291-6.

74. Klauser A, Bodner G, Frauscher F, Gabl M, Zur Nedden D. Finger injuries in extreme rock climbers. Assessment of high-resolution ultrasonography. Am J Sports Med. 1999;27(6):733-7.

75. Amis AA, Jones MM. The interior of the flexor tendon sheath of the finger. The functional significance of its structure. J Bone Joint Surg Br. 1988;70(4):583-7.

76. Serafini G, Derchi LE, Quadri P, Martinoli C, Orio O, Cavallo A, et al. High resolution sonography of the flexor tendons in trigger fingers. J Ultrasound Med. 1996;15(3):213-9.

77. Schweizer A. Lumbrical tears in rock climbers. J Hand Surg [Br]. 2003;28(2):187-9.

78. Schweizer A. Lumbrical tears in rock climbers. Journal of hand surgery. 2003;28(2):187-9.

79. Verdan C, Poulenas I. Anatomic and functional relations between the tendons of the long palmar muscle and the long flexor muscle of the thumb at their crossing in the carpus. Annales de chirurgie plastique. 1975;20(2):191-6.

80. Rohrbough JT, Mudge MK, Schilling RC, Jansen C. Radiographic osteoarthritis in the hands of rock climbers. Am J Orthop. 1998;27(11):734-8.

81. Schöffl VR, Hochholzer T, Imhoff AB, Schoffl I. Radiographic adaptations to the stress of high-level rock climbing in junior athletes: a 5-year longitudinal study of the German junior national team and a group of recreational climbers. Am J Sports Med. 2007;35(1):86-92.

82. Hochholzer T, Schöffl V. [Osteoarthrosis in fingerjoints of rockclimbers] Degenerative Veränderungen der Fingergelenke bei Sportkletterern. D Z Sportmed. 2009;60(6):145-9.

83. Allenspach P, Saupe N, Rufibach K, Schweizer A. Radiological changes and signs of osteoarthritis in the fingers of male performance sport climbers. J Sports Med Phys Fitness. 2011;51(3):497-505.

84. Schöffl V, Hochholzer T, Schöffl I. Extensor hood syndrome--osteophytic irritation of digital extensor tendons in rock climbers. Wilderness Environ Med. 2011;21(3):253-6.

85. Kellgren JH, Lawrence JS. Radiological assessment of osteo-arthrosis. Ann Rheum Dis. 1957;16:494-502. 